suspicion of discharge from the eyes of a new-born baby. In this way the authorities are enabled to see that such cases have proper treatment by a medical practitioner at an early date; and so there is no real need for the midwife to do more to the baby's eyes than clean them thoroughly with warm water.

\title{
THE INTERNATIONAL ORGANIZATION OF THE FIGHT AGAINST TRACHOMA
}

\section{Assembly of Delegates, April 18, I933, at Madrid}

Professor Dr. Emile de Grósz, the President of the Organization, in addressing the assembly of delegates spoke of the work done in combating trachoma since the first International Ophthalmological Congress held in Bruxelles in 1857. He praised the advances in prophylaxis and commented on the fact that up to date the aetiology of trachoma still eluded the investigator. Also he stated that little or no progress had been made in the treatment of this disease and recourse had to be made to old empirical therapeutic methods.

The programme of the Organization was defined at Geneva in 1930 , but the execution of this has been seriously embarrassed by the economic depression of the world. At a meeting in Paris in 1931, the executive committee decided that papers on the aetiology of trachoma should be read at the Fourteenth International Ophthalmological Congress at Madrid, and these were contributed by Messrs. MacCallan, Morax, Angelucci, Pittaluge and Thygesson. Dr. F. Wibaut read a paper on the initial symptoms of trachoma. Professor Dr. Emile de Grósz commented on the work done by the joint winners of the Royal Hungarian Government's prize for the best work on the cause of trachoma.

$\mathrm{He}$ expressed the hope that this international organization against trachoma would grow and become powerful enough to make its influence felt in a universal and practical manner.

It was decided to hold at the next meeting of the organization a discussion on prophylaxis and international co-operation. The executive committee will hold a meeting at Budapest in June, 1934 , and a plenary meeting of delegates is planned for 1935, either in Holland or Switzerland.

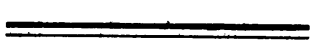

